\title{
Thermal Degradation of Cellulosic Materials ${ }^{1,2}$
}

\author{
S. L. Madorsky, V. E. Hart, ${ }^{3}$ and S. Straus
}

\begin{abstract}
Fortisan, cellulose triacetate, and $\mathrm{NO}_{2}$-oxidized cellulose were pyrolyzed in a vacuum in the temperature range $180^{\circ}$ to $465^{\circ} \mathrm{C}$. Cotton cellulose and cellulose triacetate were also pyrolyzed in nitrogen at atmospheric pressure. The tar yields were in the decreasing order from: Cotton, Fortisan, cellulose triacetate, and oxidized cellulose. The other volatiles consisted mainly of acetic acid, carbon dioxide, and carbon monoxide, from the triacetate; and water, carbon dioxide, and carbon monoxide from the other celluloses. In all cases there was a carbonaceous residue (volatilization end point), the amount depending on the nature of the cellulose and the temperature of pyrolysis. When pyrolyzed in nitrogen at atmospheric pressure, cotton cellulose and cellulose triacetate yielded less tar than when pyrolyzed in a vacuum. The tar from cellulose triacetate consisted of a compound whose infrared spectrum resembled that of the original triacetate. Cotton cellulose, Fortisan, and cellulose triacetate do not differ much in their initial rates and activation energies of thermal degradation. Oxidized cellulose has very high initial rates of thermal degradation.
\end{abstract}

\section{Introduction}

It was shown in an earlier publication [1] ${ }^{4}$ by the present authors that cotton cellulose, cotton hydrocellulose, and viscose rayon, when pyrolyzed in a vacuum, yield volatile products consisting mainly of tar, $\mathrm{H}_{2} \mathrm{O}, \mathrm{CO}_{2}$, and $\mathrm{CO}$, and also a nonvolatile carbonaceous residue. It was also shown that the main constituent of the tar from cotton cellulose was levoglucosan, which is isomeric with the structural cellulose unit, but has an oxygen linkage between the 1 and 6 carbons, in addition to the 1 to 5 oxygen linkage.

The present paper describes results of a further study of the thermal degradation of cellulosic materials, including cotton cellulose, Fortisan, cellulose triacetate, and $\mathrm{NO}_{2}$-oxidized cellulose. This study consisted in:

(1) Pyrolyzing the celluloses at various temperatures, fractionating the volatile products, and analyzing the volatile and nonvolatile fractions ${ }^{5}$ by mass-spectrometric, infrared, and microcryoscopic methods;

(2) Determining the rates of thermal degradation at various temperatures, and calculating from these rates the over-all activation energies involved in the reactions. All the experiments, except where indicated otherwise, were carried out in a vacuum of about $10^{-4} \mathrm{~mm}$ of $\mathrm{Hg}$. The experimental procedure and the apparatus used in this study are the same as those described previously [1].

\section{Materials Used}

The cotton used in this investigation was an Empire cotton obtained from the Southern Utilization Research Branch of the U. S. Department of

1 This work was performed as part of a research project sponsored by the Office of the Quartermaster General, Department of the Army, Natick, Mass.

2 This paper was presented at the 131st National Meeting of the American Chemical Society in Miami, Fla., April 7-12, 1957.

3 Present address National Institutes of Health, Bethesda, Md.

4 Figures in brackets indicate the literature references at the end of this paper. ${ }^{5}$ The following fractions were collected: (1) Residue; $(2) V_{\text {pyr }}$, volatile at the temperature of pyrolysis but not at room temperature; (3) $\mathrm{V}_{25}$, volatile at room temperature, but not at $-80^{\circ} \mathrm{C}$; (4) $\mathrm{V}-80$, volatile at $-80^{\circ} \mathrm{C}$, but not at $-190^{\circ}$
$\mathrm{C}$; (5) $\mathrm{V}-190$, volatile at $-190^{\circ} \mathrm{C}$.
Agriculture. Details of its purification have been described previously [1]. The purified cotton had a moisture content of 3.7 percent, based on the dry weight.

Fortisan, ${ }^{6}$ a regenerated cellulose, was purified by scouring for $1 \mathrm{hr}$ in an aqueous solution containing d percent $\mathrm{Na}_{2} \mathrm{CO}_{3}$ and 0.5 percent Castile soap, a1 $70^{\circ} \mathrm{C}$. This was followed by washing with distillet water and drying in air. The purified material had a moisture content of 5.24 percent, based on the dry weight.

A commercial cellulose triacetate, Arnel, ${ }^{6}$ was extracted with cold ethanol, dried in air, washed with hot distilled water, and again dried in air. The purified material was dried at $50^{\circ} \mathrm{C}$ for $30 \mathrm{~min}$. It lost 1.4 percent based on the dry weight.

The $\mathrm{NO}_{2}$-oxidized cellulose was a pure product intended for surgical use. The moisture content was determined by heating a sample in a vacuum at $50^{\circ} \mathrm{C}$ for $30 \mathrm{~min}$, and also by evacuating another sample at room temperature for $16 \mathrm{hr}$. The loss in both cases was about the same, 10.1 percent based on dry weight. Analysis for carboxyl content by the calcium acetate method showed 92.3 percent oxidation of the primary alcohol. The dried $\mathrm{NO}_{2}-$ oxidized cellulose analyzed $40.73 \mathrm{C}, 4.43 \mathrm{H}_{2}, 54.62$ $\mathrm{O}_{2}$, and $0.22 \mathrm{~N}_{2}$, as compared with a theoretical content of $41.19 \mathrm{C}, 4.71 \mathrm{H}_{2}$, and $54.10 \mathrm{O}_{2}$, calculated on the basis of 92.3 percent oxidation of the primary alcohol to carboxyl.

High-purity 2,3,4-levoglucosan-triacetate, melting: point $110^{\circ} \mathrm{C}$, was obtained from the Northern Utilization Research Branch of the U. S. Department of Agriculture.

\section{Pyrolysis Experiments}

\subsection{Fortisan}

Two pyrolysis experiments were carried out on Fortisan. The results are shown in table 1 in comparison with those previously obtained for viscose rayon and cotton cellulose [1].

6 Fortisan and Arnel are trademarked names for the completely deacetylated acetate and for cellulose triacetate fibers, respectively, of the Celanese Corporation of America. 
No mass spectrometer analysis was made of the various volatile fractions from pyrolysis of Fortisan. Since Fortisan closely resembles viscose rayon in its structure and thermal behavior it was assumed that the analyses of the fractions from Fortisan would be similar to those obtained previously for viscose rayon.

The average molecular weight of the tar from Fortisan as determined by a freezing-point lowering method in phenol was 167 , which is about the same as that found for the tar from cotton, 166. As compared with these values, the molecular weight of a structural unit of cellulose is 162 .

Fortisan and viscose rayon behave similarly during vacuum pyrolysis (see table 1), but in comparison with cotton cellulose and cotton hydrocellulose [1] they yield, in general, less tar and more

TABLE 1. Volatile fractions from pyrolysis of Fortisan, viscose rayon, and cotton cellulose

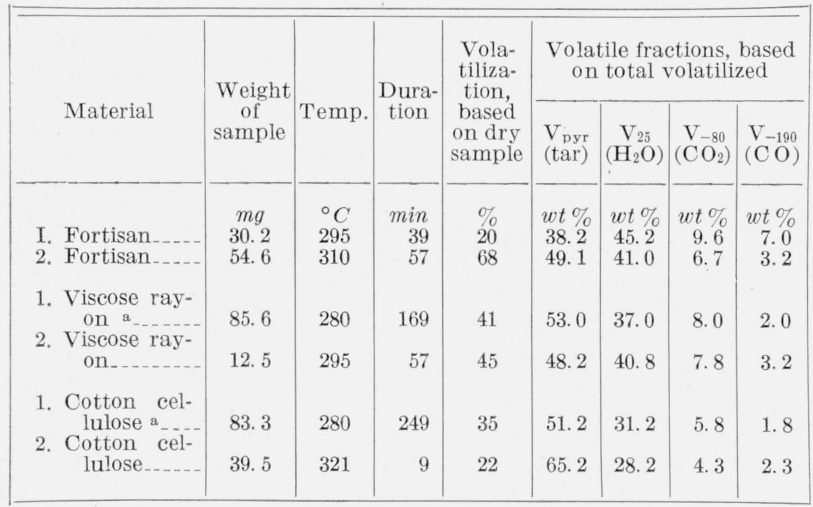

a Data for viscose rayon and cotton cellulose were taken from table 1 of reference [1]. Results for viscose rayon at $280^{\circ}$ and for cotton cellulose at $280^{\circ}$ are cumulative for experiments carried out in several consecutive steps. water. As was pointed out previously [1], such a difference could not be due to a difference in type and extent of crystallinity, nor to a difference in the degree of polymerization. However, it is possible that the difference in the thermal behavior of Fortisan and viscose rayon, as compared with cotton cellulose and cotton hydrocellulose, is caused by the greater ash content in the first two polymers. Analysis showed that cotton cellulose and hydrocellulose contained 0.06 percent ash, based on dry samples, while Fortisan contained 0.11 percent and viscose rayon 0.14 percent, on the same basis. In order to check on this point cotton was impregnated with 0.14 percent $\mathrm{Na}_{2} \mathrm{CO}_{3}$, a compound which is known to suppress the yield of tar, and pyrolyzed at $280^{\circ} \mathrm{C}$ for $149 \mathrm{~min}$. Total loss by volatilization was 15 percent, and the volatiles consisted, in weight percent, of $21 \mathrm{~V}_{\text {pyr }}, 54 \mathrm{~V}_{25}, 13 \mathrm{~V}_{-87}$, and 12 $\mathrm{V}_{-193}$. This distribution of volatiles is intermediate between that obtained from cotton cellulose alone and that from cotton impregnated with 7 percent $\mathrm{NA}_{2} \mathrm{CO}_{3}[1]$.

Venn [2] found that by washing raw cotton with water he could increase the yield of levoglucosan from 0 to 28 percent during pyrolysis at reduced pressure. Further treatment of the cotton with 1.5 percent solution of $\mathrm{NaOH}$, followed by 1 percent solution of $\mathrm{HCl}$ and a thorough washing, increased the yield to 38 percent.

\subsection{Cellulose Triacetate}

Results of pyrolysis of cellulose triacetate, alone and mixed with $\mathrm{NaCl}$ or $\mathrm{Na}_{2} \mathrm{CO}_{3}$, are shown in table 2. In experiment No. 1 the sample was pyrolyzed

TABLE 2. Volatile fractions from pyrolysis of cellulose triacetate

\begin{tabular}{|c|c|c|c|c|c|c|c|c|c|c|}
\hline \multirow{2}{*}{ Expt. No. } & \multirow{2}{*}{$\begin{array}{l}\text { Tempera- } \\
\text { ture }\end{array}$} & \multirow{2}{*}{$\begin{array}{l}\text { Weight } \\
\text { of sample }\end{array}$} & \multicolumn{2}{|c|}{ Duration } & \multicolumn{2}{|c|}{ Volatilization } & \multicolumn{4}{|c|}{$\begin{array}{l}\text { Volatile fractions, based on total } \\
\text { volatilized }\end{array}$} \\
\hline & & & For step & $\underset{\text { tive }}{\text { Cumula- }}$ & For step & $\underset{\text { tive }}{\text { Cumula- }}$ & $\mathrm{V}_{\mathrm{pyr}}$ & $\mathrm{V}_{25}$ & $\mathrm{~V}_{-80}$ & V-190 \\
\hline \multicolumn{11}{|c|}{ CELLULOSE TRIACETATE } \\
\hline $\begin{array}{l}1 \\
2-a \\
2-b \\
2-c \\
2-d\end{array}$ & $\begin{array}{c}\circ C \\
25 \text { to } 465 \\
250 \\
310 \\
310 \\
310\end{array}$ & $\begin{array}{c}m g \\
10.5 \\
43.2\end{array}$ & $\begin{array}{l}\min \\
325 \\
30 \\
56 \\
58 \\
90\end{array}$ & $\begin{array}{l}\min \\
325 \\
30 \\
86 \\
144 \\
234\end{array}$ & $\begin{array}{r}\% \\
89.6 \\
1.8 \\
33.1 \\
27.2 \\
14.3\end{array}$ & $\begin{array}{c}\% \\
89.6 \\
1.8 \\
34.9 \\
62.1 \\
76.4\end{array}$ & $\begin{array}{c}\% \\
44.5 \\
44.8 \\
48.0 \\
35.7\end{array}$ & $\begin{array}{c}\% \\
44.6 \\
47.5 \\
45.9 \\
55.5\end{array}$ & $\begin{array}{c}\% \\
6.0 \\
4.4 \\
4.0 \\
5.7\end{array}$ & $\begin{array}{l}\% \\
4.9 \\
3.3 \\
2.1 \\
3.1\end{array}$ \\
\hline \multicolumn{11}{|c|}{ CELLULOSE TRIACETATE IMIREGNATED WITH $9.1 \%$ NACL } \\
\hline $\begin{array}{l}3-\mathrm{a} \\
3-\mathrm{b} \\
4-\mathrm{a} \\
4-\mathrm{b} \\
4-\mathrm{c}\end{array}$ & $\begin{array}{l}250 \\
310 \\
250 \\
300 \\
300\end{array}$ & $\begin{array}{l}47.8 \\
20.0\end{array}$ & $\begin{array}{l}30 \\
22 \\
30 \\
25 \\
60\end{array}$ & $\begin{array}{r}30 \\
52 \\
30 \\
55 \\
115\end{array}$ & $\begin{array}{l}1.6 \\
46.9 \\
1.7 \\
38.9 \\
79.1\end{array}$ & $\begin{array}{r}1.6 \\
48.5 \\
1.7 \\
38.9 \\
79.1\end{array}$ & $\begin{array}{l}51.1 \\
51.0 \\
44.7\end{array}$ & $\begin{array}{l}45.1 \\
44.7 \\
48.7\end{array}$ & $\begin{array}{l}2.5 \\
3.7 \\
5.9\end{array}$ & $\begin{array}{l}1.3 \\
0.6 \\
0.7\end{array}$ \\
\hline \multicolumn{11}{|c|}{ CELLULOSE TRIACETATE IMPREGNATED WITH $9.0 \% \mathrm{NA}_{2} \mathrm{CO}_{3}$} \\
\hline $\begin{array}{l}5-\mathrm{a} \\
5-\mathrm{b} \\
5-\mathrm{c} \\
6 \\
7\end{array}$ & $\begin{array}{l}250 \\
250 \\
310 \\
310 \\
310\end{array}$ & $\begin{array}{l}47.0 \\
\\
44.8 \\
20.0\end{array}$ & $\begin{array}{r}22 \\
157 \\
43 \\
60 \\
60\end{array}$ & $\begin{array}{r}22 \\
179 \\
222 \\
60 \\
60\end{array}$ & $\begin{array}{r}8.2 \\
14.8 \\
44.3 \\
69.5 \\
69.3\end{array}$ & $\begin{array}{r}8.2 \\
23.0 \\
67.3 \\
69.5 \\
69.3\end{array}$ & $\begin{array}{r}13.0 \\
5.1 \\
4.8 \\
5.1 \\
5.5\end{array}$ & $\begin{array}{l}64.6 \\
75.3 \\
80.5 \\
76.9 \\
78.3\end{array}$ & $\begin{array}{l}21.0 \\
16.9 \\
11.5 \\
14.8 \\
13.1\end{array}$ & $\begin{array}{l}\text { 1. } 4 \\
2.7 \\
3.2 \\
3.2 \\
3.1\end{array}$ \\
\hline
\end{tabular}


in one step from room temperature to $465^{\circ} \mathrm{C}$. In experiments of group 2 pyrolysis was performed on the same sample in 4 consecutive steps and the products were weighed after each step. Similarly, groups of experiments 3,4 , and 5 were performed in steps. Experiments 6 and 7 were each performed in single steps.

In all experiments in which additives were used, except experiment 6 , the sample was mixed with the powdered salt and the mixture was moistened with a small drop of water in order to obtain a better distribution of the salt through the cellulose triacetate. The sample was heated in air at $80^{\circ}$ to $90^{\circ} \mathrm{C}$ to a constant weight, prior to pyrolysis. In experiment 6 the sample was intimately mixed with powdered $\mathrm{Na}_{2} \mathrm{CO}_{3}$ and the mixture used dry. The object of performing experiment 6 was to ascertain whether the heating of the wet mixture of cellulose triacetate and $\mathrm{Na}_{2} \mathrm{CO}_{3}$ at $80^{\circ}$ to $90^{\circ} \mathrm{C}$ in the other experiments had caused any deacetylation of the acetate. In experiments 6 and 7 pyrolysis was carried out under similar conditions. The results, as seen from table 3 , are quite similar.

TABLE 3. Mass-spectrometer analysis of volatile fractions from pyrolysis of cellulose triacetate

\begin{tabular}{|c|c|c|}
\hline $\begin{array}{c}\text { Experiment } \\
\text { number a }\end{array}$ & Fraction & Composition in mole percent \\
\hline 1. & $\left\{\begin{array}{l}\mathrm{V}_{25} \\
\mathrm{~V}_{-80} \\
\mathrm{~V}_{-190}\end{array}\right.$ & $\begin{array}{l}100 \mathrm{CH}_{3} \mathrm{COOH} \\
96.6 \mathrm{CO}_{2}, 2.2 \mathrm{CH}_{3} \mathrm{CHO}, 1.2 \mathrm{CH}_{3} \mathrm{COCH}_{3} \\
72.7 \mathrm{CO}, 22.6 \mathrm{CH}_{4}, 4.7 \mathrm{H}_{2}\end{array}$ \\
\hline $6 \ldots$ & $\left\{\begin{array}{l}\mathrm{V}_{25} \\
\mathrm{~V}_{-80} \\
\mathrm{~V}_{-190}\end{array}\right.$ & $\begin{array}{l}98.6 \mathrm{CH}_{3} \mathrm{COOH}, 1.4 \mathrm{CH}_{3} \mathrm{COCH}_{3} \\
100 \mathrm{CO}_{2} \\
89.2 \mathrm{CO}_{2}, 7.4 \mathrm{CH}_{4}, 3.4 \mathrm{H}_{2}\end{array}$ \\
\hline $7 \ldots$ & $\mathrm{V}_{25}$ & $96.2 \mathrm{CH}_{3} \mathrm{COOH}, 2 \mathrm{CH}_{3} \mathrm{CHO}, 1.8 \mathrm{CH}_{3} \mathrm{OH}$ \\
\hline
\end{tabular}

a Experiment numbers are the same as those given in table 2.

Mass-spectrometer analyses of the more volatile fractions are shown in table 3 for experiments 1 , 6 , and 7 . In each case fraction $V_{25}$ consists primarily of $\mathrm{CH}_{3} \mathrm{COOH}$. If the moist alkali used in experiment 7 had resulted in deacetylation, $\mathrm{H}_{2} \mathrm{O}$ would have appeared in this fraction. The absence of $\mathrm{H}_{2} \mathrm{O}$ is further proof that no appreciable deacetylation took place under the conditions employed in the preparation of samples for pyrolysis.

The tar fraction had an average molecular weight of 236, as determined by a microcryoscopic method in phenol. This is less than the molecular weight of a structural unit of cellulose triacetate, 288 .

An infrared spectrum ${ }^{7}$ of the tar obtained in the pyrolysis of cellulose triacetate is shown in figure 1 in comparison with similar spectra of the original cellulose triacetate and of 2,3,4-levoglucosan triacetate. As can be seen from this figure, the spectrum of tar (III), obtained in the pyrolysis of cellulose triacetate, resembles that of the original cellulose triacetate (II), particularly in the region below 9 microns, but is entirely unlike the spectrum of 2,3,4-levoglucosan triacetate $(\mathrm{V})$. That the tar from cellulose triacetate does not consist of levoglucosan triacetate is

7 The authors are indebted to Florence H. Forziati and M. Kathryn Wharton for obtaining the infrared spectra reported in this paper and for aiding in their interpretation.

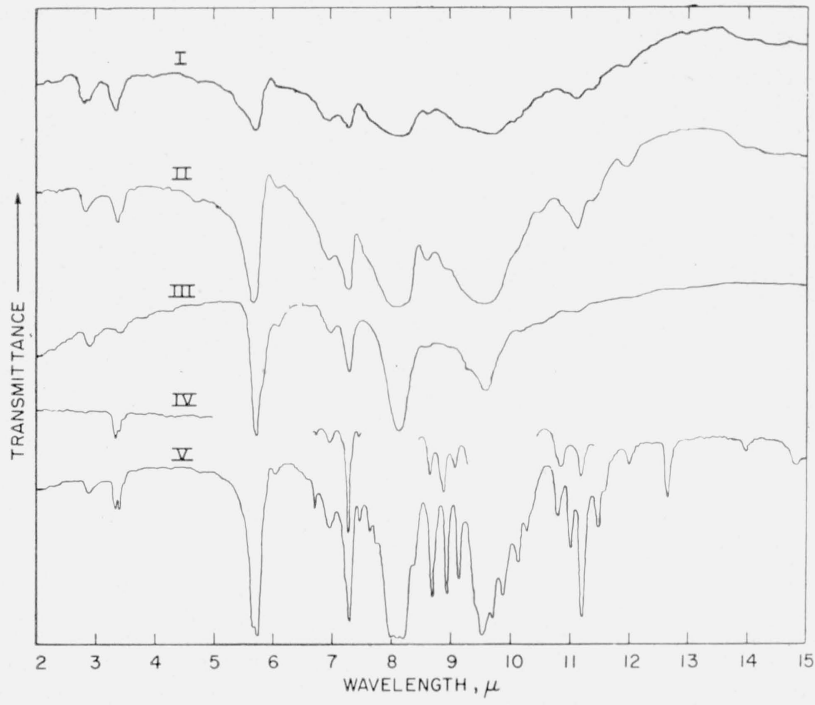

FIguRE 1. Infrared spectra of: I, Cellulose triacetate residue, after a loss of $23 \%$ by volatilization, finely dispersed in a $K \mathrm{Kr}$ pellet; $I I$, cellulose triacetate finely dispersed in a $\mathrm{KBr}$ pellet; III, a thin film prepared by evaporation of a methanolic solution of tar from pyrolysis of cellulose triacetate, on a $\mathrm{AgCl}$ plate; $\mathrm{IV}, \mathrm{aCCl}_{4}$ solution of 2,3,4-levoglucosan triacetate; V, pure 2,3,4-levoglucosan triacetate finely dispersed in a $\mathrm{KBr}$ pellet.

shown also by the fact that it is insoluble in $\mathrm{CCl}_{4}$ whereas levoglucosan triacetate is soluble. With the thought that the tar might be a mixture of levoglucosan triacetate with a component that was insoluble in $\mathrm{CCl}_{4}$, it was extracted with a small amount of $\mathrm{CCl}_{4}$ and the infrared absorption spectrum of the extract recorded. The spectrum was found to be identical with that of $\mathrm{CCl}_{4}$. Spectrum IV was obtained from a carbon tetrachloride solution of levoglucosan triacetate. Those regions of spectrum IV in which $\mathrm{CCl}_{4}$ does not absorb are shown in comparison with spectrum $\mathrm{V}$.

An infrared spectrum of a residue from cellulose triacetate, after 23 percent loss due to pyrolysis, is shown in figure 1 as spectrum I. This spectrum resembles closely that of the original cellulose triacetate (II).

In figure 2 spectra of cotton cellulose (I) and of the residue of cotton cellulose (II) remaining after 16 percent loss due to pyrolysis are shown. Here, too, there is a close resemblance between the two spectra. However, spectrum II differs from spectrum I in that it has an absorption band at approximately 5.7 microns. This band is probably attributable to one of the various types of carbonyl groups which absorb in this region.

\section{3. $\mathrm{NO}_{2}$-Oxidized Cellulose}

When heated in a vacuum, oxidized cellulose begins to lose weight at a very high rate even at low temperatures. However, this rate falls off rapidly so that it becomes necessary to raise the temperature in order to continue pyrolysis. Results of pyrolysis are shown in table 4 . Experiments 1, 2, and 3 were carried out in steps,-while in experiment 4 the 


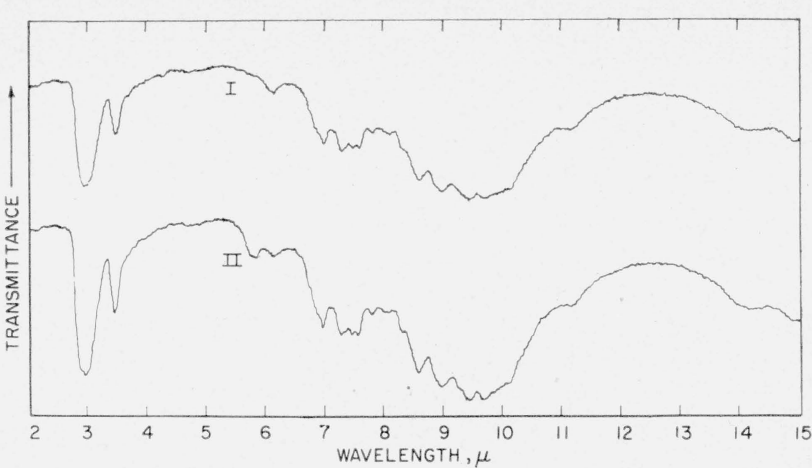

Figure 2. Infrared spectra of: I, Cotton cellulose; II, residue from cotton cellulose after a loss of $16 \%$ by volatilization. The test samples, in a finely ground state, were dispersed in $\mathrm{KBr}$ pellets.

sample was heated from room temperature to $407^{\circ} \mathrm{C}$ in one step. Unlike cotton cellulose and cellulose triacetate, oxidized cellulose yields on pyrolysis very little tar.

Mass spectrometer analysis of the more volatile fractions is shown in table 5 . The average molecular weight of the tar by a microcryoscopic determination in phenol was 157 as compared with 176 for a structural unit.

In figure 3 the infrared spectrum of a residue from $\mathrm{NO}_{2}$-oxidized cellulose after a loss of 20 percent due to pyrolysis (II) is compared with that of the original $\mathrm{NO}_{2}$-oxidized cellulose (I). Here, as in the case of cotton cellulose and cellulose triacetate there is a close resemblance between the two spectra. However, the spectrum of the residue from oxidized cellulose differs in some respects from that of the original material. In spectrum II the band at 5.7 microns is broader and the band at 6.1 microns is more intensive, relative to that at 5.7 microns, than in spectrum I. Groups that might be responsible for the increased absorption include

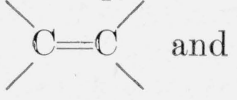
$\mathrm{C}=\mathrm{O}$ groups.

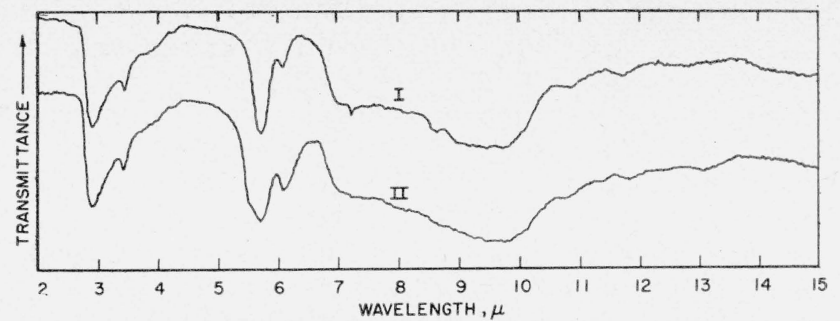

FIGURE 3. Infrared spectra of: I, $\mathrm{NO}_{2}$-oxidized cellulose; II, residue from $\mathrm{NO}_{2}$-oxidized cellulose after a loss of $20 \%$ by volatilization.

The test samples, in a finely ground state, were dispersed in $\mathrm{KBr}$ pellets.

\subsection{Cotton and Cellulose Triacetate in Nitrogen}

Pyrolyses of cotton and cellulose triacetate were carried out in nitrogen at atmospheric pressure. The same apparatus was used as in the vacuum pyrolysis. A pure grade of nitrogen, analyzing 99.8 percent $\mathrm{N}_{2}$ and 0.2 percent $\mathrm{O}_{2}$, was used. The apparatus was evacuated for about $20 \mathrm{hr}$. prior to filling it with nitrogen at atmospheric pressure. Fractions $\mathrm{V}_{\text {pyr }}$ (tar), $\mathrm{V}_{25}\left(\mathrm{H}_{2} \mathrm{O}\right.$ or $\left.\mathrm{CH}_{3} \mathrm{COOH}\right)$, and $\mathrm{V}_{-80}\left(\mathrm{CO}_{2}\right)$ were first condensed together in a liquid nitrogen trap. After evacuating the $\mathrm{N}_{2}$ from the apparatus, the fractions were separated by the same method that was used in experiments with pyrolysis in a vaccum, and then weighed. The noncondensable fraction $\mathrm{V}_{-190}$ (mostly CO) was mixed with the $\mathrm{N}_{2}$ and was not collécted. Weight of this fraction was calculated on

TABLE 5. Mass-spectrometer analysis of volatile fractions from pyrolysis of $\mathrm{No}_{2}$-oxidized cellulose

\begin{tabular}{|c|c|c|}
\hline $\begin{array}{c}\text { Experiment } \\
\text { number a }\end{array}$ & Fraction & Composition in mole percent \\
\hline $1-\mathrm{a}_{-}$ & $\left\{\begin{array}{l}V_{25} \\
V_{-80} \\
V_{-190}\end{array}\right.$ & $\begin{array}{l}98.4 \mathrm{H}_{2} \mathrm{O}, 1.2 \mathrm{CH}_{2} \mathrm{O}, 0.4 \mathrm{CH}_{3} \mathrm{OH} \\
100 \mathrm{CO}_{2} \\
\text { Fraction too small for analysis }\end{array}$ \\
\hline $4 \ldots$ & $\left\{\begin{array}{l}\mathrm{V}_{25} \\
\mathrm{~V}-80 \\
\mathrm{~V}_{-190}\end{array}\right.$ & $\begin{array}{l}91.7 \mathrm{H}_{2} \mathrm{O}, 3.8 \mathrm{CH}_{3} \mathrm{COOH}, 1.9 \mathrm{CH}_{3} \mathrm{CHO}, 1.2 \\
\mathrm{CH}_{3} \mathrm{OH}, 1.2 \mathrm{C}_{2} \mathrm{H}_{5} \mathrm{OH} \text {, trace } \mathrm{HCOOH} \\
100 \mathrm{CO}_{2} \\
99.3 \mathrm{CO}, 0.7 \mathrm{H}_{2}\end{array}$ \\
\hline
\end{tabular}

a Experiment numbers are the same as shown in table 4.

TABLE 4. Volatile fractions from pyrolysis of oxidized cellulose

\begin{tabular}{|c|c|c|c|c|c|c|c|c|c|c|}
\hline \multirow{2}{*}{$\begin{array}{l}\text { Experi- } \\
\text { ment } \\
\text { number }\end{array}$} & \multirow{2}{*}{$\begin{array}{l}\text { Tempera- } \\
\text { ture }\end{array}$} & \multirow{2}{*}{$\begin{array}{l}\text { Weight } \\
\text { of } \\
\text { sample }\end{array}$} & \multicolumn{2}{|c|}{ Duration } & \multicolumn{2}{|c|}{ Volatilization } & \multicolumn{4}{|c|}{$\begin{array}{l}\text { Volatile fractions, based on total vola- } \\
\text { tilized }\end{array}$} \\
\hline & & & $\begin{array}{l}\text { For } \\
\text { step }\end{array}$ & $\begin{array}{l}\text { Cumu- } \\
\text { lative }\end{array}$ & $\begin{array}{l}\text { For } \\
\text { step }\end{array}$ & $\begin{array}{l}\text { Cumu- } \\
\text { lative }\end{array}$ & $\mathrm{V}_{\mathrm{pyr}}$ & $V_{28}$ & $V-80$ & $\mathrm{~V}_{-190}$ \\
\hline $\begin{array}{l}1-a \\
1-b \\
1-c\end{array}$ & $\begin{array}{l}{ }^{\circ} \mathrm{C} \\
180 \\
180 \\
180\end{array}$ & $\begin{array}{c}m g \\
55.3\end{array}$ & $\begin{array}{r}\min \\
5 \\
19 \\
51\end{array}$ & $\begin{array}{r}\min \\
5 \\
24 \\
75\end{array}$ & $\begin{array}{l}\% \\
4.7 \\
7.8 \\
6.2\end{array}$ & $\begin{array}{l}\% \\
4.7 \\
12.5 \\
18.7\end{array}$ & $\begin{array}{l}\% \\
6.6 \\
3.9 \\
4.8\end{array}$ & $\begin{array}{c}\% \\
67.2 \\
54.3 \\
57.4\end{array}$ & $\begin{array}{c}\% \\
25.1 \\
40.5 \\
35.7\end{array}$ & $\begin{array}{l}\% \\
1.1 \\
1.3 \\
2.1\end{array}$ \\
\hline $\begin{array}{l}2-\mathrm{a} \\
2-\mathrm{b} \\
2-\mathrm{c} \\
2-\mathrm{d} \\
2-\mathrm{e} \\
2-\mathrm{f} \\
2-\mathrm{g}\end{array}$ & $\begin{array}{l}180 \\
211 \\
211 \\
240 \\
270 \\
300 \\
331\end{array}$ & 48.5 & $\begin{array}{r}120 \\
11 \\
93 \\
45 \\
35 \\
36 \\
57\end{array}$ & $\begin{array}{l}120 \\
131 \\
224 \\
269 \\
304 \\
340 \\
397\end{array}$ & $\begin{array}{r}20.3 \\
6.8 \\
6.6 \\
6.9 \\
7.2 \\
5.9 \\
5.0\end{array}$ & $\begin{array}{l}20.3 \\
27.1 \\
33.7 \\
40.6 \\
47.8 \\
53.7 \\
58.7\end{array}$ & $\begin{array}{l}4.6 \\
6.4 \\
8.0 \\
8.4 \\
7.5 \\
9.9\end{array}$ & $\begin{array}{l}55.3 \\
49.3 \\
41.3 \\
36.2 \\
30.2 \\
25.3\end{array}$ & $\begin{array}{l}37.7 \\
40.4 \\
44.2 \\
46.1 \\
46.1 \\
40.0\end{array}$ & $\begin{array}{r}2.4 \\
3.9 \\
6.5 \\
9.3 \\
16.2 \\
24.8\end{array}$ \\
\hline $\begin{array}{l}3-\mathrm{a} \\
3-\mathrm{b}\end{array}$ & $\begin{array}{l}200 \\
280\end{array}$ & 4.5 & $\begin{array}{l}44 \\
98\end{array}$ & $\begin{array}{r}44 \\
142\end{array}$ & $\begin{array}{l}29.8 \\
26.2\end{array}$ & $\begin{array}{l}29.8 \\
56.0\end{array}$ & $\begin{array}{r}8.3 \\
13.0\end{array}$ & $\begin{array}{l}53.0 \\
29.2\end{array}$ & $\begin{array}{l}35.6 \\
51.3\end{array}$ & $\begin{array}{l}3.1 \\
6.5\end{array}$ \\
\hline 4 & 25 to 407 & 6.1 & 132 & 132 & 66.1 & 66.1 & 4.0 & 38.5 & 51.5 & 6.0 \\
\hline
\end{tabular}


TABLE 6. Volatile fractions from pyrolysis of cotton cellulose and cellulose triacetate in a vacuum and in nitrogen

\begin{tabular}{|c|c|c|c|c|c|c|c|c|c|}
\hline \multirow{2}{*}{$\begin{array}{l}\text { Weight } \\
\text { of sample }\end{array}$} & \multirow{2}{*}{ Temp. } & \multicolumn{2}{|c|}{ Duration } & \multicolumn{2}{|c|}{ Volatilization } & \multicolumn{4}{|c|}{$\begin{array}{l}\text { Volatile fractions, based on total vol- } \\
\text { atilized }\end{array}$} \\
\hline & & For step & Cumula- & For step & $\underset{\text { tive }}{\text { Cumula- }}$ & $\mathrm{V}_{\mathrm{pyr}}$ & $\mathrm{V}_{25}$ & $V_{-80}$ & $\mathrm{~V}_{-190}$ \\
\hline \multicolumn{10}{|c|}{ COTTON CELLULOSE IN A VACUUM a } \\
\hline $\begin{array}{c}m g \\
83.3 \\
83.3 \\
83.3\end{array}$ & $\begin{array}{l}{ }^{\circ} \mathrm{C} \\
280 \\
280 \\
280\end{array}$ & $\begin{array}{c}\min \\
96 \\
153 \\
77\end{array}$ & $\begin{array}{c}\min \\
96 \\
249 \\
326\end{array}$ & $\begin{array}{r}\% \\
10.3 \\
25.0 \\
9.8\end{array}$ & $\begin{array}{c}\% \\
10.3 \\
35.3 \\
45.1\end{array}$ & $\begin{array}{c}\% \\
49.0 \\
60.3 \\
62.5\end{array}$ & $\begin{array}{c}\% \\
40.7 \\
32.0 \\
30.2\end{array}$ & $\begin{array}{l}\% \\
7.4 \\
5.9 \\
5.6\end{array}$ & $\begin{array}{l}\% \\
2.9 \\
1.8 \\
1.7\end{array}$ \\
\hline \multicolumn{10}{|c|}{ COTTON CELLULOSE IN NITROGEN } \\
\hline $\begin{array}{l}48.2 \\
48.2 \\
48.2\end{array}$ & $\begin{array}{l}280 \\
280 \\
280\end{array}$ & $\begin{array}{r}96 \\
153 \\
77\end{array}$ & $\begin{array}{r}96 \\
249 \\
326\end{array}$ & $\begin{array}{r}10.7 \\
23.6 \\
9.3\end{array}$ & $\begin{array}{l}10.7 \\
34.3 \\
43.6\end{array}$ & $\begin{array}{r}20.4 \\
17.6 \\
6.1\end{array}$ & $\begin{array}{l}63.3 \\
65.5 \\
71.0\end{array}$ & $\begin{array}{l}11.8 \\
13.0 \\
17.6\end{array}$ & $\begin{array}{l}4.5 \\
3.9 \\
5.3\end{array}$ \\
\hline \multicolumn{10}{|c|}{ CELLULOSE TRIACETATE IN A VACUUM b } \\
\hline 43. 2 & 310 & 56 & -....- & 33.1 & -..... & 44.8 & 47.5 & 4.4 & 3.3 \\
\hline \multicolumn{10}{|c|}{ CELLULOSE TRIACETATE IN NITROGEN } \\
\hline 93.5 & 310 & 56 & 56 & 35.8 & 35.8 & 7.9 & 79.4 & 6.5 & 6.2 \\
\hline
\end{tabular}

a Data are given in cumulative values, based on experiments $2 \mathrm{a}, 2 \mathrm{~b}, 2 \mathrm{c}, 2 \mathrm{~d}$, and $2 \mathrm{e}$, in table 1 of reference [1].

b These data are the same as for experiment $2 \mathrm{~b}$ in table 2 above, and are not cumulative.

the assumption that the ratio of $\mathrm{V}_{-80}$ to $\mathrm{V}_{-190}$ was the same here as in vacuum pyrolysis. This assumption appears reasonable in view of the fact that the fractions added up to give a good material balance of the sample.

When pyrolysis is carried out in a vacuum, the conditions for the escape of the volatile products from the hot zone are similar to those obtained in molecular distillation where the condenser is located near the hot zone. Under these conditions even the larger fragments, in this case the tar molecules, escape without undergoing appreciable further decomposition. However, when pyrolysis is carried out in nitrogen at atmospheric pressure, the tar molecules, due to collisions with the nitrogen molecules, will remain long enough in the hot zone so that an appreciable part of them will undergo secondary decomposition.

Results of pyrolysis of cotton cellulose and cellulose triacetate in nitrogen are shown in table $6 \mathrm{com}$ pared with results of pyrolysis of the same materials in a vacuum. As shown in this table pyrolysis in nitrogen gave a greater yield of the lighter fractions: $\mathrm{V}_{25}, \mathrm{~V}_{-80}$, and $\mathrm{V}_{-190}$, at the expense of the tar. However, the rates of volatilization and the ratio of $\mathrm{V}_{25}$ to $\mathrm{V}_{-80}$ remained about the same.

\section{Rates of Thermal Degradation}

\subsection{Fortisan and Cellulose Triacetate}

The rates of thermal degradation of Fortisan and cellulose triacetate were determined in a vacuum apparatus provided with a tungsten spring balance. The apparatus and the experimental procedure have been described previously [3]. Results for Fortisan and cellulose triacetate are shown in figures $4,5,6$, and 7 . In figures 4 and 5 percentage volatilization, referred to the dry sample, is shown plotted versus time (solid lines) for Fortisan and cellulose triacetate, respectively. The interrupted lines in these figures represent plots of logarithm of percentage residue versus time. ${ }^{8}$ The log-time plots deviate from straight lines, indicating that the over-all degradation reaction is complex and not entirely of first order. In figures 6 and 7 the rates of volatilization

${ }^{8}$ In figure 3 of our previous paper on thermal degradation of cellulose [1] the scale for the logarithm of percentage residue should read from 1 to 2 instead of from 0 to 2 .

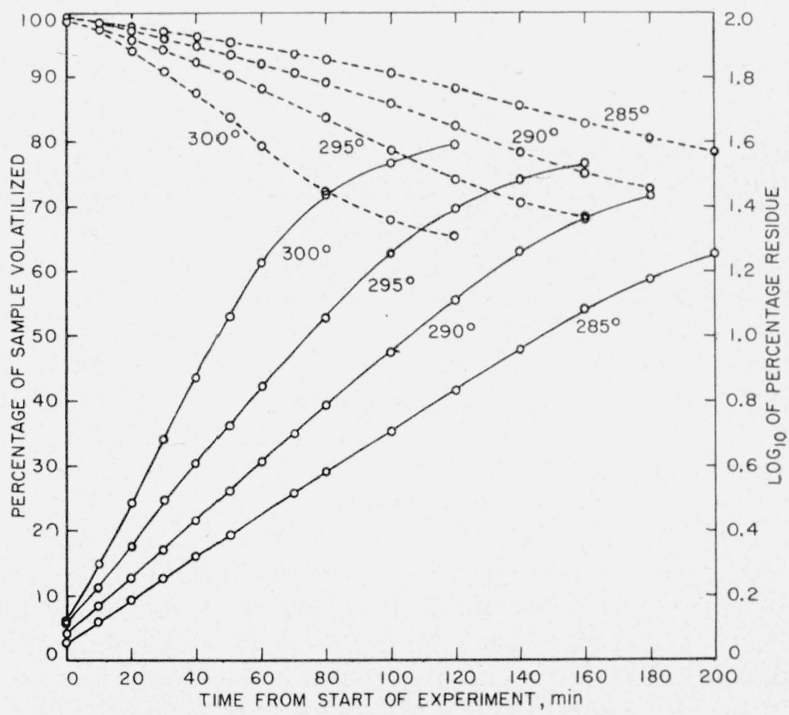

FIGURE 4. Thermal degradation of Fortisan. . Percentage of sample volatilized versus time; ......., $\log _{10}$ of percentage residue versus time. 


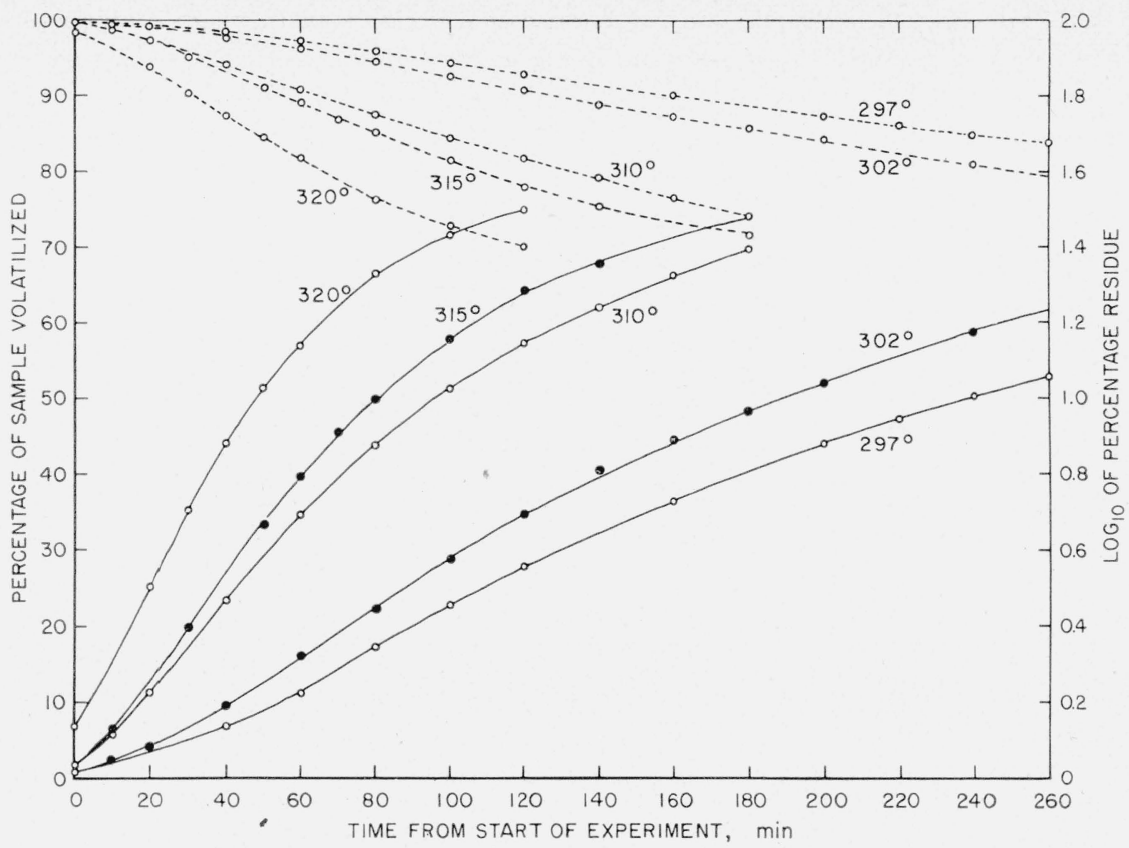

Figure 5. Thermal degradation of cellulose triacetate.

__ Percentage of sample volatilized versus time; ...., $\log _{10}$ of percentage residue versus time.

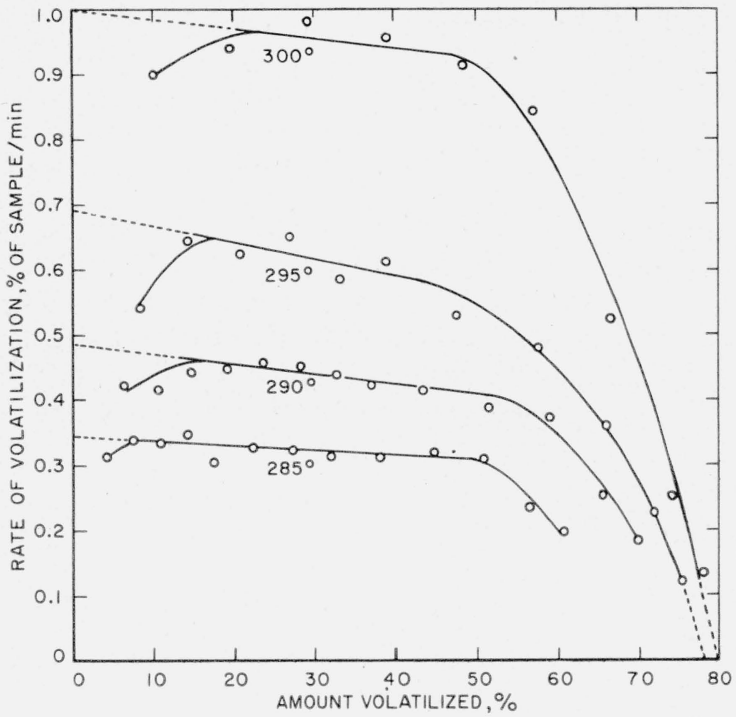

FiguRE 6. Rates of volatilization of Fortisan, in percentage of sample per minute, as a function of percentage volatilization,

in percentage of sample per minute, are plotted versus percentage volatilization. The intercepts of the extrapolated straight parts of the plots with the ordinate are defined as the apparent initial rates for the corresponding temperatures. The intercepts of the rate curves with the abscissa are defined as the carbonization end points. A carbonization end point indicates that for a given temperature volatilization approaches zero at a given percentage volatilization. However, the residue at this point is not completely carbonized. As was pointed out previously [1], in the case of cotton these residues, when heated further to about $1,000^{\circ} \mathrm{C}$, lost half of

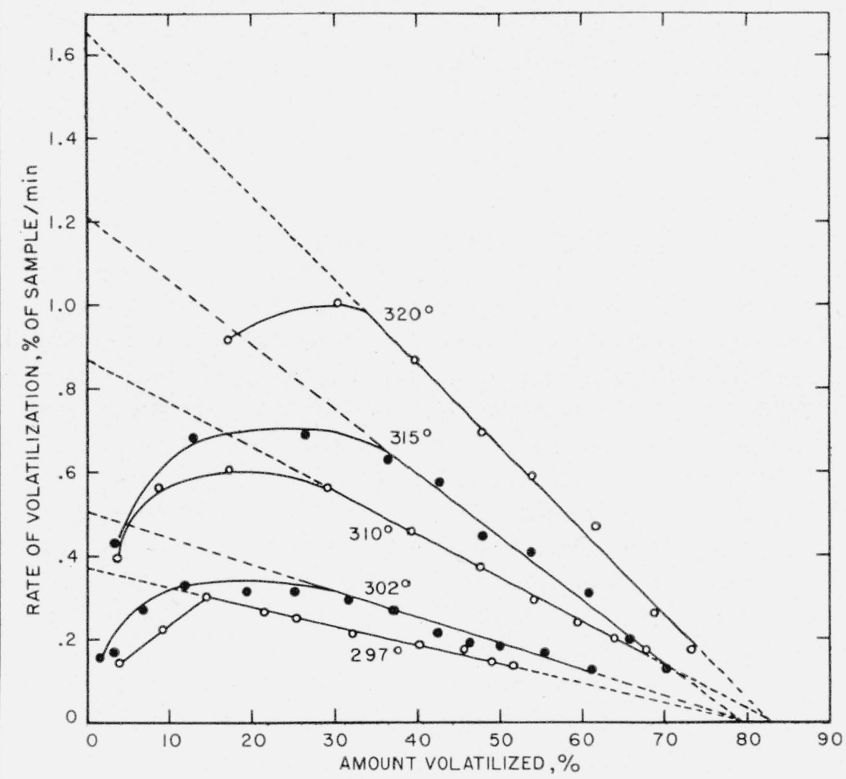

Figure 7. Rates of volatilization of cellulose triacetate, in percentage of sample per minute, as a function of percentage volatilization.

their weight. The carbonization end points for the lower temperatures for Fortisan (fig. 6) could not be obtained by extrapolation of the rate curves. However, it is apparent that these end points do not differ much from those at the higher temperatures.

By plotting the logarithm of the apparent initial rates versus the reciprocal of the absolute temperature straight lines were obtained whose slopes represent the activation energies of thermal degradation of Fortisan and cellulose triacetate. 
Numerical data for rates, carbonization end points, and activation energies for Fortisan and cellulose triacetate, are shown in table 7 . On the whole, the data do not differ much from those obtained previously for cotton cellulose, cotton hydrocellulose, and viscose rayon, without additives [1].

TABLE 7. Results of rate studies of thermal degradation of Fortisan and cellulose triacetate

\begin{tabular}{|c|c|c|c|}
\hline $\begin{array}{l}\text { Temper- } \\
\text { ature }\end{array}$ & $\begin{array}{l}\text { Apparent } \\
\text { initial rate }\end{array}$ & $\begin{array}{l}\text { Carboniza- } \\
\text { tion end } \\
\text { point }\end{array}$ & $\begin{array}{c}\text { Activation } \\
\text { energy }\end{array}$ \\
\hline \multicolumn{4}{|c|}{ FORTISAN } \\
\hline $\begin{array}{l}{ }^{\circ} \mathrm{C} \\
285 \\
299 \\
295 \\
300\end{array}$ & $\begin{array}{c}\% / \min \\
0.35 \\
.49 \\
.69 \\
1.00\end{array}$ & $\begin{array}{c}\% \\
78 \\
80\end{array}$ & $\begin{array}{c}\text { kcal/mole } \\
46\end{array}$ \\
\hline \multicolumn{4}{|c|}{ CELLULOSE TRIACETATE } \\
\hline $\begin{array}{l}297 \\
302 \\
310 \\
315 \\
320\end{array}$ & $\begin{array}{r}0.37 \\
.51 \\
.87 \\
1.21 \\
1.66\end{array}$ & $\begin{array}{l}80 \\
80 \\
82 \\
80 \\
82\end{array}$ & 45 \\
\hline
\end{tabular}

\section{2. $\mathrm{NO}_{2}$-Oxidized Cellulose}

Because of the very rapid initial loss of weight during pyrolysis it was not possible to obtain rate curves for oxidized cellulose by the loss of weight method in the tungsten spring apparatus. Instead, the rates were determined during the pyrolysis experiments (see table 4) by reading at intervals the total pressure developed in the apparatus by means of a multiplying manometer. The distribution of volatiles at the times when pressures were read are interpolated from the values given under "volatile fractions..." in table 4 . In this way loss of weight for any interval between pressure readings can be calculated, and the loss divided by the time interval gives the rate for that interval. The rates are shown plotted in figure 8. The apparent initial rate cannot be extrapolated from these curves.

\section{Discussion}

In discussing the formation of levoglucosan in the vacuum distillation of cotton cellulose [I] it was assumed that the mechanism involves a thermal scission of a $\mathrm{C}-\mathrm{O}$ link between rings, which is accompanied by a transfer of hydrogen from the primary alcohol to the oxygen of the broken $\mathrm{C}-\mathrm{O}$ link and the formation of an oxygen linkage between carbons 1 and 6 . When a similar scission takes place at a point one structural unit removed from either end formed by the first scission, the resulting fragments are levoglucosan molecules. When scissions occur further along the chain the multiple unit fragments are not volatilized.

If the mechanism of thermal degradation of cellulose triacetate were similar to that of cotton cellulose, the tar would have consisted mostly of 2,3,4-

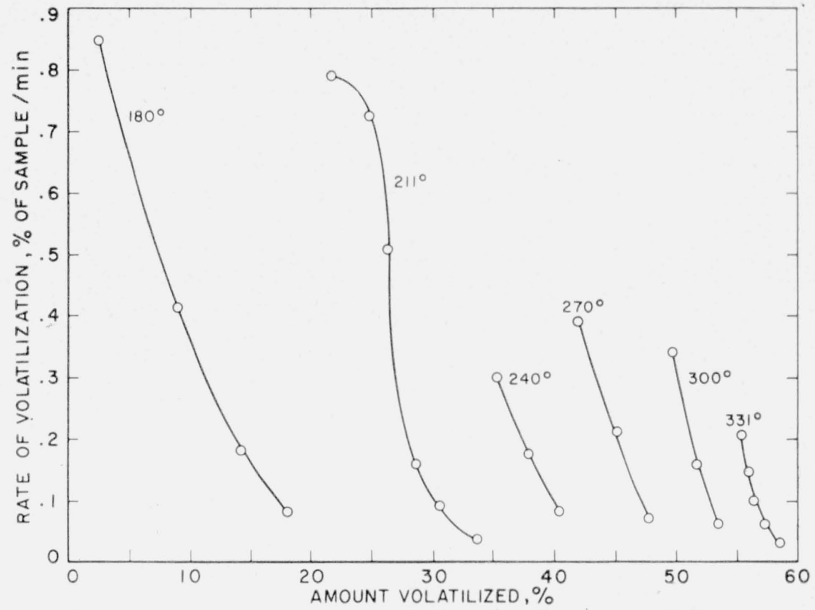

Figure 8. Rates of volatilization of $\mathrm{NO}_{2}$-oxidized cellulose, in percentage of sample per minute, as a function of percentage volatilization.

levoglucosan triacetate. Infrared analysis shows that the tar consists mainly of a molecular species which is more related to that of the original cellulose triacetate than to that of 2,3,4-levoglucosan triacetate. Further experimental work will be required to determine the chemical nature of this tar.

$\mathrm{NO}_{2}$-oxidized cellulose pyrolyzes very rapidly even at low temperatures. It seems that the whole ring structure is weakened by the oxidation of the primary alcohol so that the products consist mainly of $\mathrm{H}_{2} \mathrm{O}$, $\mathrm{CO}_{2}$, and $\mathrm{CO}$, and very little tar.

In general, it can be said that by converting the primary alcohol to an ester, formation of levoglucosan is blocked due to steric hinderance between carbons 6 and 1, while oxidation of the primary alcohol to an acid not only introduces a steric hinderance to the formation of levoglucosan but also introduces a weakness in the cellulose ring.

Addition of $\mathrm{Na}_{2} \mathrm{CO}_{3}$ to cellulose triacetate probably acts as a catalyst affecting differently the rates of formation of the various fragments so as to favor formation of $\mathrm{CH}_{3} \mathrm{COOH}$ at the expense of the tar and to speed up the over-all reaction rate. This effect of $\mathrm{Na}_{2} \mathrm{CO}_{3}$ on the pyrolysis of cellulose triacetate is similar to that on cotton cellulose [1]. However, $\mathrm{NaCl}$, while effective in reducing the tar in pyrolysis of cotton cellulose [1], had little effect on cellulose tracetate.

\section{References}

[1] S. L. Madorsky, V. E. Hart, and S. Straus, J. Research NBS 56, 343 (1956) RP 2685.

[2] H. J. P. Venn, J. Textile Inst. 15, 414 (1924).

[3] S. L. Madorsky, J. Polymer Sci. 9, 133 (1952); 11, 491 (1953).

Washington, October 21, 1957. 